\title{
Hypoxia accelerates cancer invasion of hepatoma cells by upregulating MMP expression in an HIF-1 $\alpha$-independent manner
}

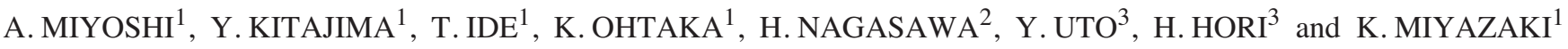 \\ ${ }^{1}$ Department of Surgery, Saga University Faculty of Medicine, 5-1-1 Nabeshima, Saga 849-8501; \\ ${ }^{2}$ Laboratory of Pharmaceutical Chemistry, Gifu Pharmaceutical University, 5-6-1 Mitahora-higashi, \\ Gifu 502-8585; ${ }^{3}$ Department of Biological Science and Technology, Faculty of Engineering, \\ The University of Tokushima, 2-1 Minamijosannjima-cho, Tokushima 770-8506, Japan
}

Received June 13, 2006; Accepted August 8, 2006

\begin{abstract}
Tumor hypoxia has been reported to induce tumor progression in several carcinomas. Current studies have shown that hypoxia inducible factor- $1 \alpha(\mathrm{HIF}-1 \alpha)$ is stabilized under hypoxic conditions and transactivates various genes related to cancer aggressiveness. In the present study, we examined whether hypoxia affects cancer invasion in hepatocellular carcinoma. We aimed to solve the molecular mechanism of tumor invasion under the hypoxic condition. We showed that tumor hypoxia accelerated cancer invasion in two hepatoma cell lines. Using Western blot and RT-PCR analyses we demonstrated striking evidence that the expression of HIF-1 $\alpha$, ETS-1, MMP-7 and MT1-MMP was strongly upregulated by hypoxic stimulation. To examine whether these invasionrelated genes are regulated by HIF- $1 \alpha$, we treated hepatoma cells with TX-402, which was reported to repress HIF-1 $\alpha$ expression. HIF-1 $\alpha$ expression was strongly repressed by the TX-402 treatment. In contrast, the expression of ETS-1, MMP-7 and MT1-MMP mRNA was not affected by TX-402 treatment. We further established stable transfectants in which HIF- $1 \alpha$ dominant negative vector was introduced into Hep3B cells (pHIF- $1 \alpha \mathrm{DN}$ ). In the pHIF- $1 \alpha \mathrm{DN}$ cells, the expression of ETS-1, MMP-7 and MT1-MMP was not repressed. Moreover, the invasion activity of pHIF- $1 \alpha \mathrm{DN}$ was not altered, compared with that of the mock. In hepatoma cells, we provided evidence that hypoxic stress accelerates cancer invasion by upregulating ETS- 1 and the MMP family by an HIF- $1 \alpha$-independent pathway.
\end{abstract}

\section{Introduction}

Most solid tumors contain regions of low oxygen tension (hypoxia) due to an imbalance in oxygen supply and

Correspondence to: Dr Kohji Miyazaki, Department of Surgery, Saga University Faculty of Medicine, Nabeshima 5-1-1, Saga 8498501, Japan

E-mail: miyazak2@post.saga-med.ac.jp

Key words: hypoxia, HIF-1 1 , invasion, MMP, hepatocellular carcinoma consumption. Although hypoxia is toxic to both cancer cells and normal cells, cancer cells undergo genetic and adaptive changes that allow them to survive and even proliferate in a hypoxic environment (1). These processes contribute to the malignant phenotype and to aggressive tumor behavior. Several in vitro studies have demonstrated that tumor hypoxia induces angiogenesis, resistance against chemotherapy and radiotherapy, evasion of apoptosis and invasion and metastasis (1-5). Also, in vivo studies have shown that human solid tumors contain regions with significantly lower oxygen tension than that found in normal tissue $(6,7)$. Furthermore, it was reported that low oxygen tension in tumors was associated with increased metastasis and poor prognosis in patients with squamous tumors of the head and neck, cervical cancers or prostate cancer (8-10).

The biological features of hypoxic tumor cells are closely related to altered gene expression under an oxygen-deficient condition. Hypoxia-inducible factor-1 (HIF-1) is a master transcription factor that plays a central role in hypoxic expression of various genes $(11,12)$. HIF-1 is a heterodimeric basic helix-loop-helix protein that consists of $\alpha$ and $\beta$ subunits. Although HIF- $1 \alpha$ and HIF-1 $1 \beta$ are constitutively expressed, HIF- $1 \alpha$ is just rapidly degraded in normoxia. Under the normoxic condition, HIF- $1 \alpha$ protein is degraded by the binding of the von Hippel-Lindau (VHL) E3 ubiquitin ligase complex. The VHL complex adds ubiquitin to HIF- $1 \alpha$, which is then degraded by proteasomes. On the other hand, under the hypoxic condition, HIF- $1 \alpha$ accumulates, dimerizes with the $\beta$ subunit, translocates to the nucleus, and initiates gene transcription. It was reported that HIF-1 regulates gene expression by binding to the hypoxia-responsive element (HRE) on target genes and that HIF-1 induces more than 40 genes under hypoxic conditions (13). For example, HIF- $1 \alpha$ activates the transcription of glycolytic enzymes such as aldolases A and C, glucose transporters such as glucose transporters 1 and 3 (GLUT-1 and GLUT-3), angiogenic molecules such as vascular endothelial growth factor (VEGF) and angiogenin and erythropoietin (EPO), which increase haemoglobin production (14). HIF-1 $\alpha$ also upregulates enzymes and proteins involved in tumor invasion and metastasis, such as urokinase-type plasminogen activator (u-PA), matrix metalloproteinase-2 (MMP-2), cathepsin D and c-met. Several reports have shown that 
HIF- $1 \alpha$ overexpression is associated with poor prognosis in several carcinomas (14). Thus, HIF- $1 \alpha$ is postulated as a key molecule in tumor progression under the hypoxic condition.

Recently, scientists have realized that hypoxia is a common and specific characteristic in human tumors and have tried to establish a therapy that targets tumor hypoxia $(15,16)$. Therefore, it is important to elucidate the molecular mechanism by which tumor hypoxia accelerates tumor progression.

We previously reported the molecular mechanisms of cancer invasion and metastasis in hepatocellular carcinoma (HCC), in which MMP expression is closely correlated with cancer progression $(17,18)$. HCC is well known as a hypervascular tumor; however, it is hypovascular in its early stage and the rapid proliferation of tumor cells continuously induces local hypoxia in its advanced stage (19). Therefore, it is possible for HCC to acquire the neovascularity and express malignant behavior under the hypoxic condition. In this study, we examined whether tumor hypoxia affects cancer invasion, and we investigated the molecular mechanism of tumor invasion under the hypoxic condition using hepatoma cell lines.

\section{Materials and methods}

Cell culture and exposure to hypoxia. Two established HCC cell lines (HepG2 and Hep3B) were purchased from Riken Cell Bank (Ibaragi, Japan). Cells were cultured in Williams E medium (Sigma, St. Louis, MO, USA), supplemented with $10 \%$ heat-inactivated fetal bovine serum (Sigma) and $100 \mu \mathrm{g} /$ $\mathrm{ml}$ kanamycin (Meiji, Tokyo, Japan) and incubated at $37^{\circ} \mathrm{C}$ in a humidified atmosphere containing $20 \% \mathrm{O}_{2}$ and $5 \% \mathrm{CO}_{2}$ in air (referred to as the normoxic condition). For the hypoxia experiments, cells were placed in a hypoxic chamber (ASTEC, Fukuoka, Japan) containing $1 \% \mathrm{O}_{2}, 5 \% \mathrm{CO}_{2}$ and $94 \% \mathrm{~N}_{2}$, and the hypoxia chamber was maintained at $37^{\circ} \mathrm{C}$ (referred to as the hypoxic condition).

Cell proliferation assay. Cell proliferation was analyzed by the MTT proliferation method. In brief, $1 \times 10^{4}$ cells/well were seeded in triplicate onto 96-well plates and incubated under the normoxic or hypoxic condition at $37^{\circ} \mathrm{C}$ in a humidified atmosphere. After $24 \mathrm{~h}$, the number of viable cells was measured in triplicate every day for 3 days using the CellTiter96 $^{\mathrm{TM}}$ non-radioactive cell proliferation assay kit (Promega, Madison, WI, USA). The proliferation curves were constructed by calculating the mean value of optical density measurements at $570 \mathrm{~nm}$ using a 96-well plate reader.

Transwell invasion assay. In vitro invasion activities through a gel matrix (Matrigel; Beckton Dickinson, Franklin Lakes, NJ, USA) were examined in 24-well plates as described previously (18). In brief, $6.5-\mathrm{mm}$ diameter polycarbonate filters $(8-\mu \mathrm{m}$ pore size) of the Falcon Transwell ${ }^{\mathrm{TM}}$ chemotaxis chambers (Beckton Dickinson) were coated with $50 \mu 1(0.2 \mathrm{mg} / \mathrm{ml})$ of Matrigel in cold Williams E (W/E) medium and dried overnight. Suspensions of $5 \times 10^{5}$ cells in $200 \mu 1$ of complete W/E medium were plated on the upper compartment of the chamber and incubated under the normoxic or hypoxic condition at $37^{\circ} \mathrm{C}$ in a humidified atmosphere. After $24 \mathrm{~h}$, noninvasive cells
Table I. PCR primers.

\begin{tabular}{|c|c|c|}
\hline Gene & Sequence & $\begin{array}{l}\text { Fragment } \\
\text { size }(b p)\end{array}$ \\
\hline \multicolumn{3}{|c|}{ Motility candidate genes } \\
\hline $\mathrm{HGF}$ & $\begin{array}{l}\text { 5'-GCCTGAAAGATATCCCGACA } \\
\text { 3'-TTCCATGTTCTTGTCCCACA }\end{array}$ & 525 \\
\hline c-met & $\begin{array}{l}\text { 5'-ACCTTGGTGCAGAGGAGCAAT } \\
\text { 3'-TAGAGCCATGTTGATGTTATC }\end{array}$ & 313 \\
\hline mts1 & $\begin{array}{l}\text { 5'-TTTGATCCTGACTGCTGTCATGGC } \\
\text { 3'-AGAGGAGTTTTCATTTCTTCCTGG }\end{array}$ & 340 \\
\hline RhoA & $\begin{array}{l}\text { 5'-ATGCTTGCTCATAGTCTTCAG } \\
\text { 3'-CAGAGCAGCTCTCGTAGCCAT }\end{array}$ & 483 \\
\hline $\mathrm{nm} 23$ & $\begin{array}{l}\text { 5'-AAGCAGCTGGAAGGAACC } \\
\text { 3'-CAATGTGGTCTGCCCTCC }\end{array}$ & 497 \\
\hline CD44 & $\begin{array}{l}\text { 5'-CAACTCCATCTGTGCAGCAAA } \\
\text { 3'-GTAACCTCCTGAAGTGCTGCTC }\end{array}$ & 307 \\
\hline integrin $\beta 1$ & $\begin{array}{l}\text { 5'-CTGAAAGACAAGTATGTTGAG } \\
\text { 3'-GAATGTGACTAGTGTGAAACA }\end{array}$ & 584 \\
\hline integrin $\beta 4$ & $\begin{array}{l}\text { 5'-GCGACTATGAGATGAAGGTG } \\
\text { 3'-GTGAGTTGTAGTCCCGTGTG }\end{array}$ & 707 \\
\hline integrin $\beta 4$ & $\begin{array}{l}\text { 5'-CCCCTACAACGTGGACACTGA } \\
\text { 3'-GCTGTCTGGAAAGTGTGACCC }\end{array}$ & 310 \\
\hline
\end{tabular}

Invasion candidate genes

E-cadherin 5'-TCGACACCCGATTCAAAGTGG 3'-TTCCAGAAACGGAGGCCTGAT

Occludin 5'-CGGCGAGCGGAATTGGTTTAT 3'-AGGAGAGGTCCATTTGTAGAA

Snail 5'-TATGCTGCCTTCCCAGGCTTG 3'-ATGTGCATCTTGAGGGCACCC

SIP1 5'-GGAAGACAAGCTTCATATTGC 3'-ATGGCTGTGTCACTGCGCTGA

ETS-1 5'-TCAGCCTGAAAGGTGTAGAC 3'-AATCCGAGGTATAGCGGGATT

MMP-1 5'-GATGTTCAGCTAGCTCAGGAT 3'-AAGGGATTTGTGCGCATGTAG

MMP-2 5'-CTTCTTCAAGGACCGGTTCAT 3'-GCTGGCTGAGTAGATCCAGTA

MMP-3 5'-TATCACTCACTCACAGACCTG 3'-TCCTTGCTAGTAACTTCATAT

MMP-7 5'-ATGGGGAACTGCTGACATCAT 3'-CCAGCGTTCAaTCCTCATCGAA

MMP-9 5'-CAACATCACCTATTGGATCC 3'-CGGGTGTAGAGTCTCTCGCT

TIMP-2 5'-GGCGTTTTGCAATGCAGATGTAG 3'-CACAGGAGCCGTCACTTCTCTTG

MT1-MMP 5'-CTAAGACCTTGGGAGGAAAAC 3'-AAGCCCCATCCAAGGCTAACA

uPA 5'-AAGAGTGCATGGTGCATGAC 3'-CTTGCGTGTTGGAGTTAAGC

HIF-1 $\alpha$-related genes

HIF-1 $\alpha$ 5'-GAAGTGTACCCTAACTAGCCG

$\begin{array}{ll}\text { 3'-GACTGAGGAAAGTCTTGCTAT } \\ \text { Erythropoietin } & \text { 5'-TGTTGGTCAACTCTTCCCAGC }\end{array}$

GLUT-1 5'-ACTGGGCAAGTCCTTTGAGAT 3'-GTCCTTGTTGCCCATGATGGA

Internal marker

B-actin 5'-TTAAGGAGAAGCTGTGCTACG 3'-GTTGAAGGTAGTTTCGTGGAT 
A

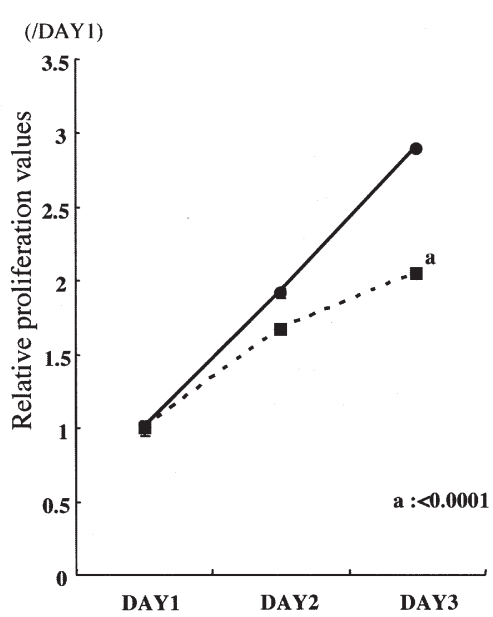

B

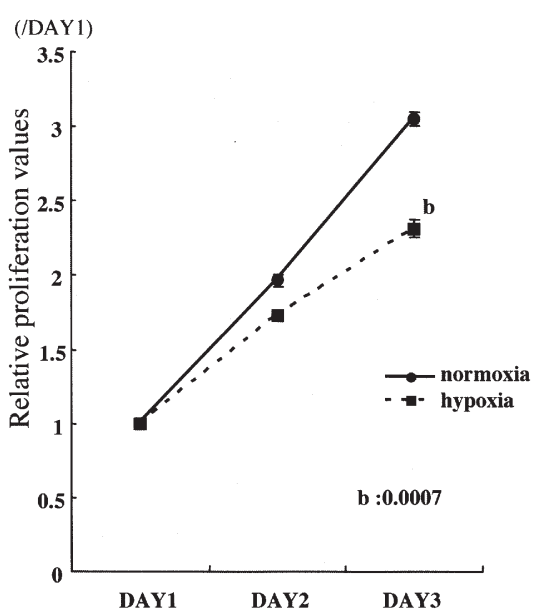

Figure 1. MTT proliferation assays were performed under the normoxic and hypoxic conditions using HepG2 (A) and Hep3B cells (B). MTT activity was measured in triplicate on days 1,2 and 3. The proliferation curves were illustrated by plotting mean value \pm standard deviation of the triplicate measurements calculated by optical density at $570 \mathrm{~nm}$ in a 96-well plate reader. Relative proliferation values on day 2 and 3 were shown as a ratio to OD570nm on day 1 . On day 3 , relative proliferation values of the hypoxic condition significantly decreased compared with that of the normoxic condition ( $\mathrm{a}$, $\mathrm{p}<0.001 ; \mathrm{b}, \mathrm{p}=0.007)$.

on the upper surface of the filters were removed completely by wiping the filter surface with a cotton swab. Viable invaded cells, which adhere to the lower surface of the filter, were fixed using $70 \%$ ethanol, and the nuclei were stained using hematoxylin. Then, the number of invaded cells was counted. These experiments were performed in triplicate and independently repeated at least three times.

$R T-P C R$. HepG2 and Hep3B cells were independently incubated under the normoxic or hypoxic condition for up to $24 \mathrm{~h}$, and total RNA was isolated from each cell line using Isogen (Nippongene, Toyama, Japan). Reverse transcriptionpolymerase chain reaction (RT-PCR) amplification was performed using a commercial RNA LA PCR kit (AMV) version 1.1 (Takara Biochemicals, Shiga, Japan). The RNA samples $(1 \mu \mathrm{g})$ were converted into cDNA using random primers and reverse transcriptase. Amplification by PCR was performed according to the manufacturer's instructions. The thermal cycles were: denaturing at $94^{\circ} \mathrm{C}$ for $30 \mathrm{sec}$, annealing at $60^{\circ} \mathrm{C}$ for $30 \mathrm{sec}$, and extension at $72^{\circ} \mathrm{C}$ for $90 \mathrm{sec}$. The sequences of the PCR primer pair and the fragment size are shown in Table I. All reactions were repeated three times.

Western blot analysis. Cell lysate was extracted from the cells incubated under the normoxic or hypoxic condition. In some experiments, cells were treated with $100 \mu \mathrm{M} \mathrm{CoCl}_{2}$, which is reported to induce HIF-1 $\alpha$ expression, as a positive control. Aliquots of each cell extract containing $30 \mu \mathrm{g}$ of protein were resolved by $10 \%$ SDS-PAGE, and the separated extracts were electrophoretically transferred onto Hybond ${ }^{\mathrm{TM}}$ ECL $^{\mathrm{TM}}$ membranes (Amersham Pharmacia Biotech, Buckinghamshire, UK) in a transfer buffer. The membrane was incubated with anti-HIF-1 $\alpha$ antibody (clone H1 $\alpha 67,1: 1000$ dilution; Novus Biologicals, Littleton, CO) and anti- $\beta$-actin (clone AC-15, 1:1000 dilution; Sigma).

Treatment with TX-402. TX-402 (3-amino-2-quinoxalinecarbonitrile-1,4-di-N-oxide) was synthesized by H. Nagasawa,
Y. Uto, and H. Hori. TX-402, a hypoxic cytotoxin, was reported to inhibit the expression of HIF-1 $\alpha$ (20). TX-402 was dissolved in $0.1 \%$ dimethylsulfoxide (DMSO) before treatment. Cells were seeded in $75-\mathrm{cm}^{2}$ flasks at a density of $1 \times 10^{6}$ cells per flask and then incubated under the normoxic condition. After $24 \mathrm{~h}$ of incubation, TX-402 was added in $8 \mathrm{ml}$ of culture medium. The control treatment was DMSO $(0.1 \%)$ alone. Then, the cells were placed in normoxic or hypoxic chambers for $20 \mathrm{~h}$. After the treatment, the cultures were harvested for isolation of total RNA or extraction of whole cell proteins.

Establishment of a stable transfectant using HIF-1a dominant negative vector. HIF- $1 \alpha$ dominant negative vector (pHIF$1 \alpha \mathrm{DN}$ ) was provided by Dr T. Matsui (Laboratory of Genomics and Proteomics, Faculty of Pharmacy and Pharmaceutical Science, Fukuyama University, Japan). Hep3B cells were cotransfected at a molar ratio of 1:10 using lipofectamine reagent (Invitrogen, Carlsbad, CA, USA) and pHIF- $1 \alpha \mathrm{DN}$ along with pcDNA3.1 vector (Promega), which encodes the neomycin resistance gene. The cells were cultured under G418 stress at 200 800 $\mu \mathrm{g} / \mathrm{ml}$ concentration (Promega). After 2 weeks of incubation, individual G418-resistant colonies were subjected to subcloning using a cloning ring (Iwaki, Chiba, Japan). As a control, empty pcDNA3.1 vector (Promega) was transfected into Hep3B cells, and the established cells were used as mock transfectants.

Statistical analysis. Results of the MTT proliferation assay and the invasion assay were statistically analyzed using the Student's t-test to compare the normoxia and hypoxia conditions or the mock and HIF-1 $\alpha-\mathrm{DN}$ transfectants. P values $<0.05$ were considered statistically significant.

\section{Results}

Effects of hypoxia on cell proliferation and invasion. To compare cell proliferation under the normoxic and hypoxic 
A

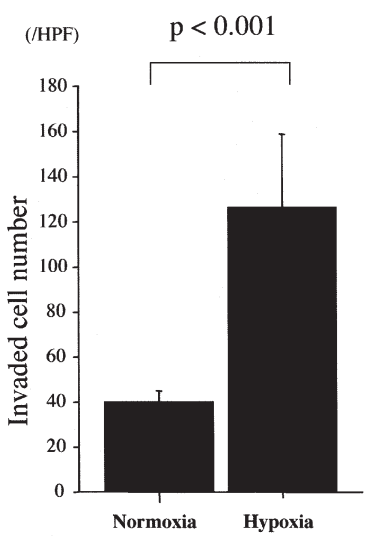

B

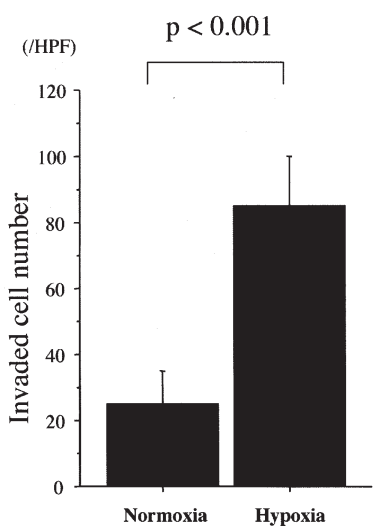

Figure 2. Invasion ability under the normoxic and hypoxic conditions was analyzed in the transwell invasion assay using HepG2 (A) and Hep3B cells (B). Data are presented as mean value \pm standard deviation of the triplicate measurements. Hypoxic cells showed significantly higher invasive properties compared with normoxic cells ( $\mathrm{p}<0.001)$ in both cell lines.

A

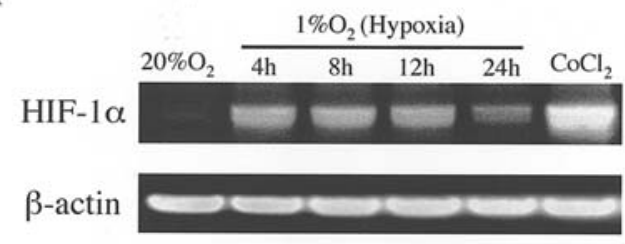

B

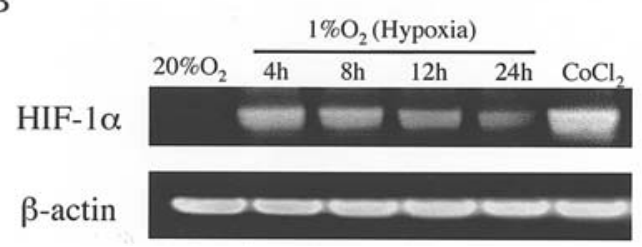

Figure 3. Western blots showed that HIF-1 $\alpha$ proteins were induced under the hypoxic condition in HepG2 (A) and Hep3B cell lines (B). Treatments with $\mathrm{CoCl}_{2}(100 \mu \mathrm{M})$ were performed as a positive control. B-actin protein levels were used as an internal marker.

conditions, we performed MTT proliferation assays. As shown in Fig. 1, cell proliferation under the hypoxic condition was decreased compared to the normoxic condition, with a statistically significant decrease on day 3 . On the other hand, the invasion activity of both cell lines was significantly increased under the hypoxic condition as compared with that of the normoxic cells (Fig. 2).

Expression of HIF-1a under the hypoxic condition. We performed Western blot analysis to examine the expression of HIF- $1 \alpha$ under the hypoxic condition. HIF- $1 \alpha$ protein expression was induced in both cell lines after $4 \mathrm{~h}$ of exposure to hypoxia (Fig. 3).

Examination of candidate genes relating to cell motility and invasion affected by the hypoxic condition. To identify invasion-related genes that are activated by the hypoxic condition, RT-PCR analysis using primer sets (Table I) for

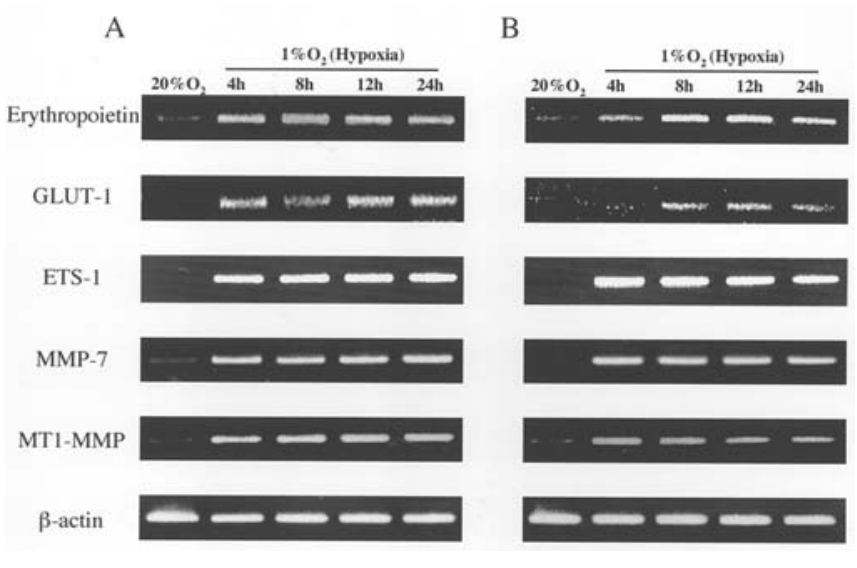

Figure 4. RT-PCR was performed to examine the effects of hypoxia on gene expression in HepG2 (A) and Hep3B (B) cells. The expression of erythropoietin and GLUT-1, which are target genes of HIF-1 $\alpha$, was induced under the hypoxic condition. Among the candidate genes related to cancer invasion, the expression levels of ETS-1, MMP-7, and MT1-MMP were upregulated under the hypoxic condition. $\beta$-actin levels were used as an internal marker.

A

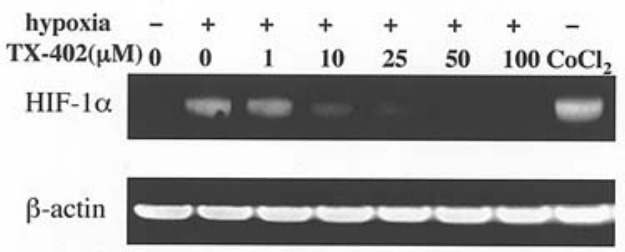

B

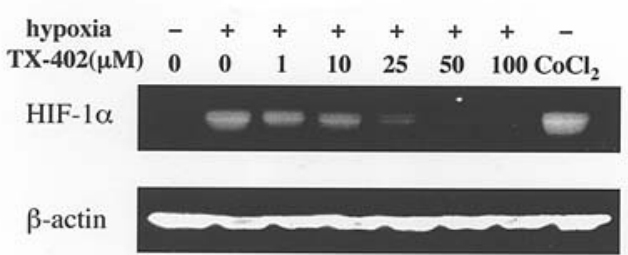

Figure 5. Western blots revealed that TX-402 repressed HIF-1 $\alpha$ proteins in a dose-dependent manner in both cell lines (A, HepG2; B, Hep3B). Treatments with $\mathrm{CoCl}_{2}(100 \mu \mathrm{M})$ were performed as a positive control. B-actin protein levels were used as an internal marker.

candidate genes was performed. For motility genes, there were no apparent differences in the expression of HGF, c-met, $\mathrm{mts} 1, \mathrm{RhoA}, \mathrm{nm} 23, \mathrm{CD} 44$, integrinß4 and integrina4 under the normoxic and hypoxic conditions. Expression of the integrin $\beta 1$ gene was not observed in any cells (data not shown).

Expression levels of erythropoietin and GLUT-1, which are reported as target genes of HIF-1 $\alpha$ were increased under the hypoxic condition (Fig. 4). Among the invasion-related genes, the expression levels of ETS-1, MMP-7 and MT1MMP were remarkably elevated under the hypoxic condition compared with the normoxic condition (Fig. 4). However, there were no differences in the expression of E-cadherin, occludin, snail, SIP-1, TIMP2 and uPA. Expression of MMP-1, MMP-2, MMP-3 or MMP-9 was not found in any cells (data not shown).

Effect of TX-402 on HIF-1a and hypoxia induced-gene expression. We examined the effect of TX-402 on HIF-1 $\alpha$ 


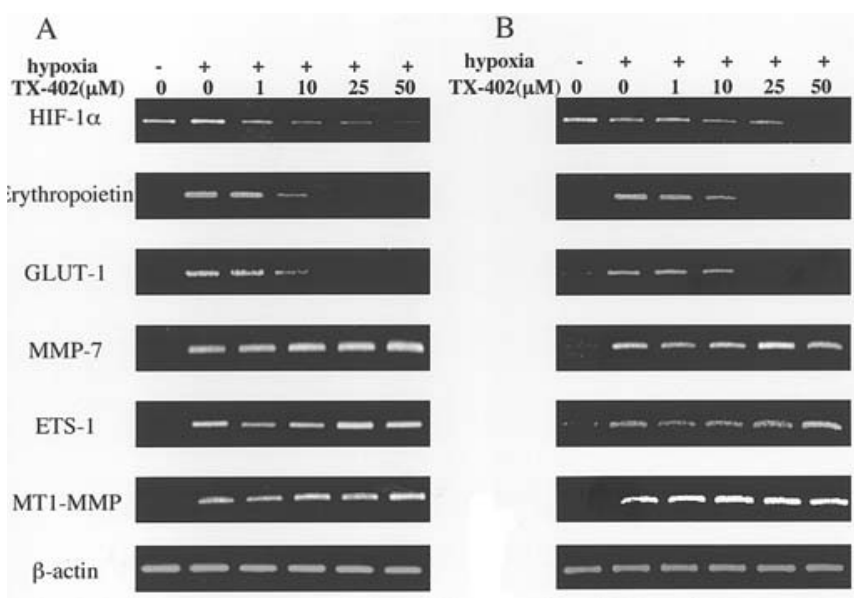

Figure 6. RT-PCR showed that TX-402 repressed the expression of HIF-1 $\alpha$, erythropoietin and GLUT-1, but not ETS-1, MMP-7 and MT1-MMP, in both cell lines (A, HepG2; B, Hep3B). B-actin levels were used as an internal marker.

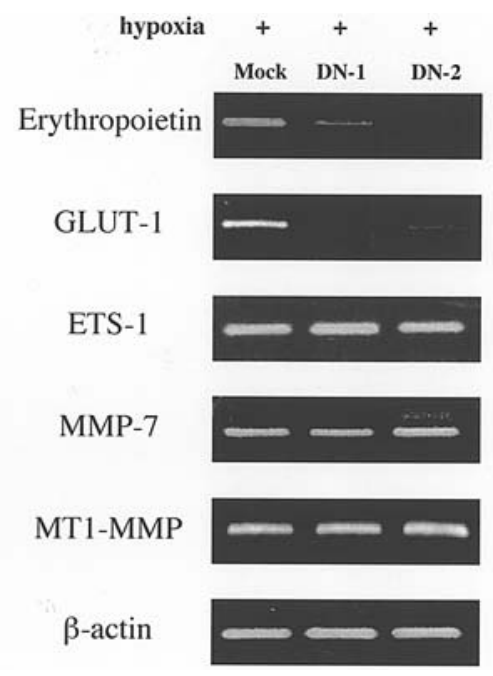

Figure 7. Hep3B cells were transfected with HIF-1 $\alpha$ dominant negative vector (pHIF-1 $\alpha \mathrm{DN}$ ). Individual cell clones were isolated after selection by G-418 (DN-1, -2). In the pHIF-1 $\alpha$ DN transfectant, the expression levels of erythropoietin and GLUT-1, but not ETS-1, MMP-7 and MT1-MMP, were repressed compared with the mock transfectant under the hypoxic condition. B-actin levels were used as an internal marker.

using hepatoma cell lines. As shown in Fig. 5, HIF-1 $\alpha$ proteins in both cell lines were repressed in a dose-dependent manner by treatment with TX-402.

We also analyzed the expression of the hypoxia-induced genes after treatment with TX-402. Conventional RT-PCR revealed that TX-402 repressed not only HIF-1 $\alpha$ mRNA, but also erythropoietin and GLUT-1 mRNA expression in a dosedependent manner (Fig. 6).

On the other hand, the expression of ETS-1, MMP-7 and MT1-MMP was not affected by treatment with TX-402 (Fig. 6).

Expression of hypoxia-induced genes and invasion activity in the pHIF-1aDN transfectant. We used RT-PCR to examine the expression of several genes in the pHIF- $1 \alpha \mathrm{DN}$ transfectant. Under the hypoxic condition, the pHIF- $1 \alpha \mathrm{DN}$ transfectant

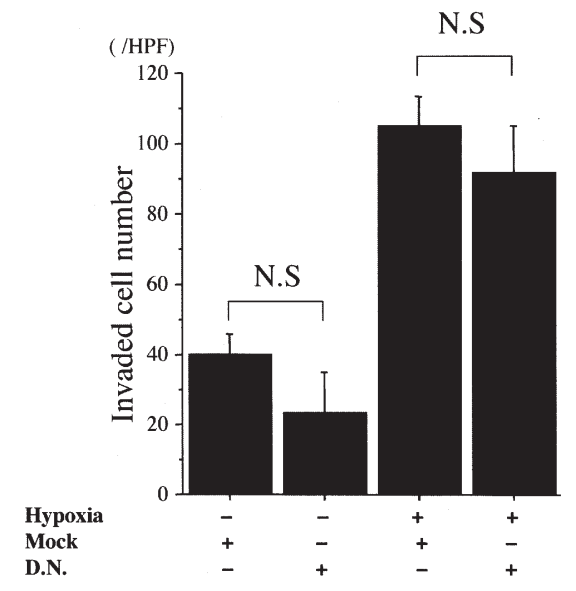

Figure 8. Invasion abilities of pHIF- $1 \alpha \mathrm{DN}$ transfectant under the hypoxic condition did not significantly decrease compared with the mock transfectant. Data are presented as mean value \pm standard deviation of the triplicate measurements.

showed repression of erythropoietin and GLUT-1 expression, but not ETS-1, MMP-7 and MT1-MMP expression (Fig. 7). These results show that HIF- $1 \alpha$ does not regulate ETS-1, MMP-7 and MT1-MMP genes under the hypoxic condition. We then analyzed the invasion activity of the pHIF- $1 \alpha \mathrm{DN}$ transfectant under normoxic and hypoxic conditions. There was no change in the invasive activity between the pHIF- $1 \alpha \mathrm{DN}$ transfectant and the mock transfectant under the normoxic and hypoxic conditions (Fig. 8).

\section{Discussion}

Haung et al recently demonstrated in an immunohistochemical analysis that HIF-1 $\alpha$ expression is significantly correlated with VEGF expression, microvessel density and the prognosis of patients with HCC (21). The authors suggested that tumor hypoxia induced neovascularization and increased tumor progression, leading to a poor prognosis in HCC. Another report showed that the surviving cells in HCC nodules pretreated with transarterial chemoembolization (TAE) grow faster than those in neighboring nodules and become resistant to subsequent TAE treatment (22). These reports suggested that the hypoxic environment in a tumor is a critical event for the acceleration of tumor progression and malignancy in HCC.

In the present study, we examined whether hypoxia affects tumor progression, especially cancer invasion, in hepatoma cells and analyzed the molecular mechanism by which tumor hypoxia increases cancer invasion in HCC. We examined cell proliferation under hypoxic conditions using HepG2 and Hep3B cells. MTT proliferation assays showed that hypoxia inhibited cell proliferation. This result supports the previous report that hypoxia induced a delay in the cell cycle by blocking G1 to S progression (23). On the other hand, we found that the invasion activities of both cell lines were significantly accelerated by hypoxic stimulation. We analyzed the alterations in the expression of invasion-related genes during hypoxic stimulation. HIF- $1 \alpha$ is a well-known transcription factor that regulates various genes under tumor hypoxia. Western blot analysis revealed that HIF-1 $\alpha$ proteins were immediately induced in both cell lines, supporting 
previous reports of HIF- $1 \alpha$ stabilization under hypoxic conditions. We next examined the expression levels of 22 candidate genes related to cancer invasion using RT-PCR analysis. In addition, we also analyzed the expression of EPO and GLUT-1, which are known target genes of HIF-1 $\alpha$ during hypoxic stimulation. Among the candidate genes, we found that the expression levels of ETS-1, MMP-7 and MT1-MMP were upregulated under the hypoxic condition. We confirmed the upregulation of these genes by quantitative RT-PCR analysis (data not shown). It was previously reported that the expression of u-PA, MMP-2, cathepsin D and c-met were transcriptionally regulated by HIF-1 $\alpha$ (14). However, the expression levels of these genes were not increased under the hypoxic condition in HepG2 and Hep3B cells. It was also reported that HIF- $1 \alpha$ regulated ETS- 1 expression by binding to the HRE on the promoter of ETS-1 (24). ETS-1 was reported to regulate the expression of the MMP family, including MMP-7 (25). The MMP family is known to play a key role in the tumor invasion of various human cancers including HCC (26). Increased expression of MMP-7 and MT1-MMP has a strong association with dedifferentiation, portal invasion, intrahepatic metastasis and recurrence (27-29). Therefore, we hypothesized that HIF-1 $\alpha$ expression was induced under the hypoxic condition and upregulated ETS-1 expression, which led to increased expression of MMP-7. These molecular events might contribute to HCC invasion accelerated under the hypoxic condition.

To clarify this hypothesis, we inhibited HIF- $1 \alpha$ expression under the hypoxic condition by treatment with an HIF-1 $\alpha$ inhibitor, TX-402. TX-402 is a bioreductive drug that selectively induces p53-independent apoptosis of tumor cells under the hypoxic condition (30). Also, TX-402 repressed HIF-1 $\alpha$ mRNA and protein expression in several carcinoma cells and led to the suppression of VEGF and GLUT-3 mRNA expression (20). We analyzed whether or not the upregulation of ETS-1, MMP-7 and MT1-MMP under hypoxia is inhibited by TX-402. We performed Western blot analysis to examine the expression of HIF-1 $\alpha$ protein after treatment with TX-402. HIF-1 $\alpha$ protein was dramatically repressed in a dose-dependent manner by treatment with TX-402. RT-PCR analysis showed that the expression of EPO and GLUT-1 was suppressed after treatment with TX-402. However, the expression levels of ETS-1, MMP-7 and MT1-MMP were not affected by the treatment. These results suggested that the expression of ETS-1, MMP-7 and MT1-MMP genes was independent of the HIF-1 $\alpha$ signal pathway.

We also established a stable transfectant using the HIF-1 $\alpha$ dominant negative vector ( $\mathrm{pHIF}-1 \alpha \mathrm{DN}$ ) to confirm that the expression of ETS-1, MMP-7 and MT1-MMP is independent of HIF-1 $\alpha$. The expression of EPO and GLUT-1 was repressed in the pHIF- $1 \alpha \mathrm{DN}$ transfectant; however, the expression of ETS-1, MMP-7 and MT1-MMP was not downregulated under the hypoxic condition. Furthermore, the invasion activity of the pHIF- $1 \alpha \mathrm{DN}$ transfectant did not decrease under the hypoxic condition compared with the mock transfectant. These results suggest that the induction of ETS-1, MMP-7 and MT1-MMP genes under the hypoxic condition was independent of HIF-1 $\alpha$ expression. In HepG2 and Hep3B cells, HIF-1 $\alpha$ does not seem to control cancer invasion through ETS-1, MMP-7 and MT1MMP genes under the hypoxic condition.
Various reports have highlighted that HIF-1 $\alpha$ is a central factor promoting tumor progression under the hypoxic environment. However, it has been reported that several genes are not directly regulated by HIF-1 $\alpha$ under the hypoxic condition. VEGF, which is known to be a target gene of HIF$1 \alpha$, was induced by hypoxia through the HIF- $1 \alpha$-independent pathway in colon cancer (31). Also, Pichiule et al reported that hypoxia-driven angiopoietin-2 expression was independent of the HIF-1 $\alpha$ pathway (32). Coffey et al demonstrated that resistance to hypoxia-induced apoptosis was not dependent on HIF- $1 \alpha$ stabilization in prostate cancer cells (33). These findings suggest the existence of HIF- $1 \alpha$-independent mechanisms that regulate tumor progression under the hypoxic condition. Like HIF-1 $\alpha$, HIF- $2 \alpha$ accumulates in the presence of hypoxia, forms a hetero dimmer with HIF-1 $\alpha$ and binds to hypoxic response elements. It was reported that several genes were regulated by HIF- $2 \alpha$ but not HIF- $1 \alpha$ under hypoxia (34). Further investigation is necessary to elucidate the HIF$1 \alpha$-independent pathway that modulates the invasion activity of HCC under tumor hypoxia including HIF-2 $\alpha$.

In conclusion, we demonstrated that tumor hypoxia accelerates cancer invasion by upregulating the expression of ETS-1 and MMPs in HCC cells. These findings suggested a novel invasion pathway under tumor hypoxia by which HIF$1 \alpha$ expression is not mediated.

\section{Acknowledgements}

We thank Dr T Matsui for kindly providing the HIF-1 $\alpha$ DN vector.

\section{References}

1. Harris AL: Hypoxia - A key regulatory factor in tumor growth. Nat Review 2: 38-47, 2001

2. Akakura N, Kobayashi M, Horiuchi I, et al: Constitutive expression of hypoxia inducible factor- $1 \alpha$ renders pancreatic cancer cells resistant to apoptosis induced by hypoxia and nutrient deprivation. Cancer Res 61: 6548-6554, 2001.

3. Hockel M and Vaupel P: Tumor hypoxia: definitions and current clinical, biologic, and molecular aspects. J Natl Cancer Inst 93: 266-276, 2001.

4. Krishnamachary B, Berg-Dixon S, Kelly B, et al: Regulation of colon carcinoma cell invasion by hypoxia-inducible factor 1 Cancer Res 63: 1138-1143, 2003.

5. Turuo T, Naito M, Tomida A, Fujita N, Mashima T, Sakamoto H and Haga N: Molecular targeting therapy of cancer: drug resistance, apoptosis and survival signal. Cancer Sci 94: 15-21, 2003.

6. Knocke TH, Weitmann HD, Feldmann HJ, Selzer E and Poter R: Intratumoral $\mathrm{pO}_{2}$-measurements as predictive assay in the treatment of carcinoma of the uterine cervix. Radiother Oncol 53: 99-104, 1999.

7. Vaupel P, Thews O, Kelleher DK and Konerding MA: O(2) extraction is a key parameter determining the oxygenation status of malignant tumors and normal tissues. Int J Oncol 22: 795-798, 2003.

8. Hockel M, Schlenger K, Aral B, Mitze M, Schaffer U and Vaupel P: Association between tumor hypoxia and malignant progression in advanced cancer of the uterine cervix. Cancer Res 56: 4509-4515, 1996.

9. Stadler P, Becker A, Feldmann HJ, Hansgen G, Dunst J, Wurschmidt F and Molls M: Influence of the hypoxic subvolume on the survival of patients with head and neck cancer. Int $\mathbf{J}$ Radiat Oncol Biol Phys 44: 749-754, 1999.

10. Movas B, Chapman JD, Greenberg RE, et al: Increasing levels of hypoxia in prostate carcinoma correlate significantly with increasing clinical stage and patient age. Cancer 89: 2018-2024, 2000 . 
11. Zhong H, Marzo AM, Laughner E, et al: Overexpression of hypoxia-inducible factor $1 \alpha$ in common human cancers and their metastases. Cancer Res 59: 5830-5835, 1999.

12. Semenza GL: HIF-1: mediator of physiological and pathophysiological responses to hypoxia. J Appl Physiol 88: 1474-1480, 2000

13. Semenza GL: HIF-1 and tumor progression: pathophysiology and therapeutics. Trends Mol Biol 8 (suppl): S62-S67, 2002.

14. Semenza GL: Targeting HIF-1 for cancer therapy. Nature Rev 3: 721-732, 2003

15. Wouters BG, Weppler SA, Koritzinsky M, et al: Hypoxia as a target for combined modality treatments. Eur J Cancer 38: 240-257, 2002

16. Powis $\mathrm{G}$ and Kirkpatrick L: Hypoxia inducible factor- $1 \alpha$ as a cancer drug target. Mol Cancer Ther 3: 647-654, 2004.

17. Miyoshi A, Kitajima Y, Sumi K, Sato K, Hagiwara A, Koga Y and Miyazaki K: Snail and SIP1 increase cancer invasion by upregulating MMP family in hepatocellular carcinoma cells. $\mathrm{Br}$ J Cancer 22: 1265-1273, 2004.

18. Miyoshi A, Kitajima Y, S Kido, Shimonishi T, Matsuyama S, Kitahara K and Miyazaki K: Snail accelerates cancer invasion by upregulating MMP expression and is associated with poor prognosis of hepatocellular carcinoma. Br J Cancer 92: 252-258, 2005.

19. Kim KR, Moon HE and Kim KW: Hypoxia-induced angiogenesis in human hepatocellular carcinoma. J Mol Med 80: 703-714, 2002.

20. Nagasawa H, Mikamo N, Nakajima Y, Matsumoto H, Uto $Y$ and Hori H: Antiangiogenic hypoxic cytotoxin TX-402 inhibits hypoxia-inducible factor 1 signaling pathway. Anticancer Res 23: 4427-4434, 2003.

21. Huang GW, Yang LY and Lu WQ: Expression of hypoxiainducible factor $1 \alpha$ and vascular endothelial growth factor in hepatocellular carcinoma: impact on neovascularization and survival. World J Gastroenterol 21: 1705-1708, 2005.

22. Gwak GY, Yoon JH, Kim KM, Lee HS, Chung JW and Gores GJ: Hypoxia stimulates proliferation of human hepatoma cells through the induction of hexolinase II expression. J Hepatology 42: 358-364, 2005

23. Gardner LB, Li Q, Park MS, Flanagan WM, Semenza GL and Dang CV: Hypoxia inhibits G1/S transition through regulation of p27 expression. J Biol Chem 276: 7919-7926, 2001.
24. Oikawa M, Abe M, Kurosawa H, Hida W, Shirato K and Sato Y: Hypoxia induces transcription factor ETS-a via the activity of hypoxia-inducible factor-1 Biochem Biophys Res Commun 289: 39-43, 2001.

25. Ozaki I, Mizuta T, Zhao G, et al: Involvement of the ETS-1 gene in overexpression of matrilysin in human hepatocellular carcinoma. Cancer Res 60: 6519-6525, 2000.

26. Nabeshima K, Inoue T, Shimano Y and Sameshima T: Matrix metalloproteinases in tumor invasion: Role for cell migration. Pathol Int 52: 255-264, 2002.

27. Harada T, Arii S, Mise M, et al: Membrane-type matrix metalloproteinase-1 (MT1-MMP) gene is overexpressed in highly invasive hepatocellular carcinomas. J Hepatology 28: 231-239, 1998.

28. Maatta M, Soini Y, Liakka A and Autio-Harmainen H: Differential expression of matrix metalloproteinase (MMP)-2, MMP-9, and membrane type 1-MMP in hepatocellular and pancreatic adenocarcinoma: Implications for tumor progression and clinical prognosis. Clin Cancer Res 6: 2726-2734, 2000

29. Yamamoto H, Itoh F, Adachi $Y$, Sakamoto H, Hinoda $Y$ and Imai K: Relation of enhanced secretion of active matrix metalloproteinase with tumor spread in human hepatocellular carcinoma. Gastroenterology 112: 1290-1296, 1997

30. Nagasawa H, Yamashita M, Mikamo N, Shimamura M, Oka S, Uto $\mathrm{Y}$ and Hori $\mathrm{H}$ : Design, synthesis and biological activities of antiangiogenic hypoxic cytotoxin, triazine-N-oxide derivatives. Comp Biochem Physiol A Mol Integr Physiol 132: 33-40, 2002.

31. Mizukami Y, Li J, Zhang X, Zimmer MA, Iliopoulos O and Chung DC: Hypoxia-inducible factor-1-independent regulation of vascular endothelial growth factor by hypoxia in colon cancer. Cancer Res 64: 1765-1772, 2004.

32. Pichiule P, Chaves JC and LaManna JC: Hypoxic regulation of angiopoietin-2 expression in endothelial cells. J Biol Chem 279: 12171-12180, 2004

33. Coffey RNT, Morrissey C, Taylor CT, Fitzpatrick JM and Watson RWG: Resistance to caspase-dependent, hypoxia-induced apoptosis is not hypoxia-inducible factor-1 alpha mediated in prostate carcinoma cells. Cancer 103: 1363-1374, 2005.

34. Wang V, Davis DA, Haque M, Huang LE and Yarchoan R: Differential gene up-regulation by hypoxia-inducible factor- $1 \alpha$ and hypoxia-inducible factor- $2 \alpha$ in HEK293T cells. Cancer Res 65: 3299-3306, 2005. 